\title{
25-Hydroxyvitamin D3 Measurement
}

National Cancer Institute

\section{Source}

National Cancer Institute. 25-Hydroxyvitamin D3 Measurement. NCI Thesaurus. Code C156529.

The determination of the amount of 25-hydroxyvitamin D3 present in a sample. 